\title{
Lexikalisierung von grammatischen Mitteln in der heutigen ungarischen Sprache
}

1. Es wird oft und mit Recht behauptet, dass viele Sprachen ihre einstige Mannigfaltigkeit an Flexionsformen im Laufe ihrer Ausbildung zu modernen Kultursprachen eingebüsst haben; als Beispiel bzw. Beweis dieser Entwicklung pflegt man sich vor allem auf die englische Sprachgeschichte zu berufen. Viel seltener wird dagegen erwähnt, dass Z.B. das Ungarische sein bereits in der Urzeit reiches Flexionssystem - was die Nomen betrifft - während des langen Prozesses seiner relativen Anpassung an die ostmitteleuropäischen arealen kulturellen Sprachverhältnisse entschieden weiterentwickelt hat, und dass sich dieser Vorgang in mehreren Details selbst heute noch klar beobachten lässt. (Vgl. CIFU 2, 538-43.)

Im folgenden möchte ich vor allem darauf hinweisen, dass auf der allerneuesten Entwicklungsstufe dieser grössten finnischugrischen Sprache in beschränktem Masse auch ein ganz anderer, ebenfalls entgegengesetzter Vorgang zu verzeichnen ist: es werden nämlich aus manchen Suffixen bzw. Präfixen unter Beibehaltung ihrer Hauptfunktionen - selbständige Lexeme, vorwiegend Substantive. Dieses Phänomen hängt aber mit einer allgemeineren, wohlbekannten Erscheinung der modernen Sprachen zusammen, nämlich mit der auf ähnliche sprachpsychologische Faktoren, ähnliche sprachliche (grammatische) Kultur, zum Teil sogar auf eine gemeinsame internationale stilistische Mode zurückgehenden Funktions- und Wortartverschiebung mancher Verhältnis- bzw. Hilfswörter (Formwörter). Ich denke hier vor allem an die Substantivierung von Bindewörtern, aber auch an die viel seltenere Verselbständigung von Hilfsverben und Postpositionen. Da nun dieser 
Vorgang sich zeitlich zuerst bei den Bindewörtern erfassen lässt, und er auch heute am meisten dort verbreitet ist, möchte ich vor allem auf die Verwandlung dieser Wortart eingehen.

Es soll ebenfalls gleich hier erwähnt werden, dass ich die Substantivierung von Konjunktionen in der ungarischen Sprache bereits ziemlich ausführlich erörtert (s. Magyar Nyelvőr 86 [1962], 265-82; 1976: Anyanyelvi olvasókönyv 131-43), mich kurz sogar auch mit dem ganzen jetzigen Problemkreis befasst habe (s. Magyar Nyelv 74 [1978]). Die dabei erzielten Ergebnisse sind jedoch meines Erachtens auch für die Forscher anderer moderner - vor allem gleichfalls finnisch-ugrischer - Sprachen aufschlussreich, so dass sie es wert sind, auch den das Ungarische nicht beherrschenden Fachleuten zugänglich gemacht zu werden. Das ist also der Zweck dieses Aufsatzes, allerdings ohne den Anspruch auf eine lückenlose Aufzählung der hierher gehörenden sprachlichen Einheiten. - Und noch etwas soll bereits in dieser Einleitung klar gesagt werden: ich behandle die Form und den Inhalt (Bedeutung bzw. grammatische Funktion) der betreffenden sprachlichen Elemente in ihrem dialektischen Zusammenhang, also nicht streng voneinander getrennt.

2. Die Verselbständigung der Konjunktionen kann nicht auf einen einzigen Grund zurückgeführt werden; sehen wir jedoch einen der wichtigsten Gründe näher an. Es ist durchaus natürlich, dass der Sprechende seine aktuelle Äusserung öfters - wegen verschiedener äusserer oder innerer Umstände - plötzlich unterbricht, besonders in emphatischem Wortwechsel. Dieser Riss im Redeablauf erfolgt in den entsprechend aufgebauten Sätzen möglichst $\mathbf{n}$ a $\mathbf{c h}$ dem Bindewort: "Várok rád, de . . "' ("'Ich warte auf dich, aber/doch . . ." '); "Teljesítem a kivánságod, ha ..." ('"'Ich erfülle deinen Wunsch, falls/wenn ...'’). Es fehlt also der zweite Teil der durch die Konjunktion verbundenen syntaktischen Einheiten (im erwähnten Fall sind diese Gliedsätze), während der einleitende Teil explizit ausgedrückt ist:

$$
\text { Vorderteil + Bindewort + (Leerstelle) }
$$

Wenn nun die Redepause nach der Unterbrechung für den Hörer zu lange dauert, so kann dieser den Partner drängen, 
seine Mitteilung zu beenden; am effektvollsten, indem er die zuvor schon gehörte, die syntaktische bzw. logische Relation des Folgenden ohnehin bestimmende Konjunktion mit fragendem bzw. ungeduldig aufforderndem Tonfall wiederholt: "De?"'; "Ha . . .". Das Schema ist dann also:

(Bekannter Vorderteil) + Urgierender Bindewortsatz + (Erwarteter Abschluss)

Und wenn der ursprünglich Sprechende nun seine Mitteilung zu beenden beschliesst, beginnt er seine Worte zumeist wiederum mit derselben Konjunktion:". . de csak délig" ",. . . aber lediglich bis Mittag" '); ". . . ha te is megirod a levelet" (" "... wenn/falls auch du den Brief schreiben wirst"'). Da fehlt also der aus dem Kontext schon bekannte einleitende Teil des vollständigen zusammengesetzten Satzes, doch nicht das ebenso bereits bekannte Bindewort:

(Bekannter Vorderteil) + Bindewort + Abschliessender Teil

Und daher gehört auch der Fall, wo der Redepartner sich vom bisherigen Thema abwendet oder ohne jedes vorangegangene Gespräch seinen Vorschlag bzw. seine Frage mit einem zumeist adversativen Bindewort beginnt: "Hanem van egy javaslatom" (" "Aber ich habe einen Vorschlag" '); "De mire várunk még?" ('"Doch worauf warten wir noch?"'). Das Schema ist dann also:

(Leerstelle als Vorderteil) + Bindewort + Abschliessender Teil

Die eigenartige syntaktische und logische Funktionsbedeutung der Konjunktion ist in ähnlichen Sprechsituationen bestimmt auch ohne besondere grammatische Kenntnisse leicht $\mathrm{zu}$ erfassen. Somit kann die wachsende Häufigkeit solcher ihrer Form nach unvollständigen Sätze es ungemein erleichtern, dass die Sprachgemeinschaft das Bindewort einfach anstelle des diesem wahrscheinlich zugehörenden einleitenden bzw. abschliessenden Satzsegmentes gebraucht, es am Ende - besonders nach entsprechender grammatischer bzw. logischer Bildung - symbolisch sogar als abstrakten, substantivischen 
Ausdruck der einschlägigen syntakt is ch-logis chen Relation verwendet.

Dieser Vorgang geht natürlich bei jeder Konjunktion und auf jeder sozial-kulturellen Stufe in anderem Rhythmus vor sich. Auch das braucht nicht besonders begründet zu werden, dass Dichter und Schriftsteller - ganz zu schweigen von Reportern - mit dem verschiedenartigen Gebrauch der auf ungleichen Stufen der Verselbständigung oder gar der abstrakten Substantivierung stehenden Bindewörter eine ungemein mannigfaltige stilistische Wirkung erzielen können. In meinen schon angegebenen ungarischen Aufsätzen zu diesem Thema gibt es reichlich diesbezügliche Zitate. Wenn ich nun im weiteren einige davon wiederholen muss, so werde ich den genauen Fundort nicht mehr angeben. Ebenso lasse ich diesmal die spärliche frühere ungarische Fachliteratur über dieses Thema nach Möglichkeit unerwähnt. - Im allgemeinen lässt sich ohne Übertreibung feststellen, dass der Stil durch die so angewendeten Konjunktionen gewöhnlich gedrungener, hastiger, lebensnäher und moderner wird.

Wie in anderen Sprachen sind die ungegliederten B inde worts ät $\mathrm{ze}$ in der heutigen ungarischen Konversation ziemlich beliebt. 'Írtam egy cikket" - mondja [a szerzö] óvatosan. _ "A radiobiológusról?" - "Is" (' "Ich schrieb einen Artikel"' - sagt er [der Autor] bedacht. _ "Über den Radiobiologen?", _ ' Auch [über ihn]" ') lesen wir in einer Novelle von Árpád Thiery. - "Igen. Tehát. Ám elöbb valami mást'" (' 'Ja. Also. Doch zuerst etwas anderes"') hört der Zuschauer aus dem Munde eines psychoanalytischen Scharlatans in einem Schauspiel von Gyula Illyés. - "Tehát?"' - kérdezte röviden [K.] ("'Also?" - fragte [K.] kurz') - findet man in einer Novelle von László Erdős aus dem Jahre 1962. - Az utca embere azt hiszi, hogy . . a lócsaták höse - boldog . . . Holott? ('Der Mann von der Strasse meint, dass der Held der Pferderennen glücklich ist. Wo doch . . .?') - schreibt in seinen Memoiren der in meiner Jugend bekannte Journalist Andor Kellér. - Um einen Vorwurf zurückzuweisen, sagt man häufig: 'És?' oder "És!' (', Und? / Wenn schon!" '). Wenn man die Begründung für eine Handlung o.ä. auf eine diesbezügliche Frage mit 
"Miért?" (',Warum?"') nicht angeben will (kann), antwortet man - zwar etwas ungehobelt - mit dem Wortsatz: 'Mert!" (', Darum!"').

Die adversativ-disjunktive (= alternative) Doppelkonjunktion vagy-vagy ('entweder-oder') drückt oft als Satz aus, dass die beiden Möglichkeiten, um welche es sich handelt, einander ausschliessen. So sagt ein Held von Mór Jókai, dem beliebtesten Romanschreiber des vorigen Jh.s: "Egy lapra van téve minden. Vagy - vagy -?"' ("'Alles ist auf eine Karte gesetzt. Entweder - oder?"'). Der Poet Mihály Babits fasst die in einem Gedicht seines Altersgenossen Endre Ady gegebene Alternative ebenso zusammen: Vagy, vagy! Während einer Sitzung im Jahre 1977 war zu hören: ' a . . . törvény megalkotásánál az elmélet vagy a gyakorlat szakemberei vitték-e a vezetö szerepet?" - "Is-is"' (' Spielten beim Schaffen des Gesetzes die Theoretiker oder die Experten der Praxis die führende Rolle?"' - 'Sowohl [diese] als auch [jene]" ').

In anderen Satztypen vertritt die charakteristische Konjunktion den entsprechenden Gliedsatz bzw. das einschlägige Syntagma und kennzeichnet damit den Stil, die Situation, zum Teil den ganzen Seelenzustand bzw. die Eigenart einer oder mehrerer Personen. So kommen besonders die etwas umständlichen konzessiven Bindewörter - quasi im Telegrammstil - bei einem heuchlerischen Helden von József Lengyel vor: 'Noha, jóllehet, ámbár ... de én megbocsátok" ('"Zwar, obwohl, wenn auch . . . ich vergebe doch" '). Oft muss der Schriftsteller seinen Standpunkt - oder den seines Helden - dadurch interpretieren, dass er die verwendete Konjunktion erklärt, begründet, verstärkt oder verwirft. Szabad légyen ezekröl $a^{\prime}$ szép és kellemetes dolgokrol bizonyos Minthával szollani még most . . . Nem ezekböl az okokbol szollok . . . Minthával ('Es sei mir gestattet, von diesen schönen und angenehmen Dingen mit einem gewissen "als ob" zu sprechen . . . Ich spreche nicht aus diesen Gründen mit "als ob" ') - kann man schon 1796 lesen. (S. A' Magyar Nyelv-mivelö Társaság' Munkáinak Elsö darabja. S. 31.) Tibor Déry fügt seinem ausweichenden Gliedsatz mit azaz ('das heisst') hinzu: [Reagálásomban] már az "azaz" is a gyávaság felelete ('[In meiner Reaktion] ist auch 
schon das "das heisst" eine Antwort der Feigheit'). László Németh sagt von einem schwer verständlichen de ('aber') eines oft phantasierenden ältlichen Professors: Emögött $a$ " de" mögött . . nagy ködök tornyosultak ('Hinter diesem "aber" türmten sich riesige Nebel auf'). Der Humorist László Tabi sagte über den Werbetext einer Lebensversicherung, in dem unter anderem zu lesen stand, man solle eine Versicherung abschliessen, da wir "hiszen" ('ja') Menschen sind: $E z \quad a$ "hiszen", ez aztán feldúlta bensömet, mert . . hogy "hiszen" emberek vagyunk, az mégis megrenditett, .. . ez a "hiszen" már valóságos fenyegetés ('Dieses "ja", das hat aber mein Inneres aufgewühlt, denn dass wir "ja" Menschen sind, das hat mich erschüttert, dieses "ja" ist schon eine wahre Drohung'). Ein Intellektueller grübelt in einem Roman von László Bóka folgendermassen: Ámbár . . . nem! nincs ámbár ('Obzwar . . . Nein, es gibt kein obzwar'). Iván Boldizsár gibt dieses Gespräch wider: "És?" - kérdezem. - "Nincs és" (' "Und?" frage ich. - "Es gibt kein und [= keine unausgesprochene Fortsetzung]' ').

Das einfache Herausheben der Konjunktion aus ihrem Kontext findet man ziemlich oft, wo sie - gewöhnlich als Hinweis auf die syntaktisch-logische Relation eines oder mehrerer folgender Sätze - als Titel von Gedichten usw. dient. So kommen in der neueren ungarischen Literatur Gedichte unter dem Titel vor: Ha; És; Mégis ('Doch'); Mégsem ('Doch nicht'); De ('Aber/Jedoch'); Mintha ('Als ob'); etwas seltener auch Ellenben ('Aber/Im Gegenteil'); Mert ('Weil/Da'); manchmal sogar wiederholt: És, és; Mégis, mégis, mégis; És mégis; usw. Ähnliche Überschriften können aber auch über Zeitungsglossen u.ä. stehen. Im Jahre 1976 gab es auch einen Film mit dem Titel Pedig ('Obzwar'). Ein Zeitungsartikel (Magyar Nemzet vom 9. 4. 1978) führt den Titel $A z$ "és" meg a "vagy" ('Das "und"' und das "oder" '): darin wird erörtert, dass die begründeten Ansprüche der Gesellschaft nicht mit der alternativen Konjunktion vagy-vagy ('entweder-oder'), sondern durch das kopulative és ('und') erwogen werden müssen. - In dieser Rolle ist das Bindewort schon eher als richtiges Substantiv wie in den Sätzen des vorigen Absatzes angewendet; doch bezieht es sich noch 
immer auf konkrete Texte, wo sein Gebrauch unerlässlich ist.

Am frühesten festigte sich das Bindewort ha ('das Wenn, die Bedingung') in der Rolle eines relativ abstrakten Substantivs: das neue Historisch-etymologische Wörterbuch des Ungarischen (TESz.) registriert diese Entwicklungsphase seit 1532. Es ist meines Erachtens anzunehmen, dass dahinter das Beispiel des lateinischen abstrakten si der Logik wirkte. In der neueren Gemeinsprache kommen oft sprichwortähnliche Sätze wie $A$ ha csak ha (marad) ('Das Wenn ist [bleibt] immer ein Wenn'); Ha az a ha nem volna, minden másképp volna ('Wenn es dieses Wenn nicht gäbe, würde alles anders stehen'*). Zsigmond Móricz schrieb in einem seiner frühen Romane: sokszor fordul meg egy ha-n az élet (etwa: 'Oft ändert sich das Leben infolge eines Wenn'). Ein Held von Mátyás Tímár sagt: "Most mi mondjuk ki a hákat"' (' 'Jetzt bestimmen wir die Wenn [= Bedingungen]' '). Und selbst der Sprachforscher Dezső Pais meditierte 1963 in der von ihm redigierten Zeitschrift Magyar Nyelv wie folgt: Azt a lehetöséget . . nem hárítanám el, ha . . . Tudniillik több ha is meríthetö fel ('Ich würde jene Möglichkeit nicht ablehnen, we n n . . Es können nämlich mehrere W e $\mathrm{n} \mathbf{n}$ aufgeworfen werden'). - Aus diesem Substantiv wurde dann das selten gebrauchte Verb ha-zni $\sim$ há-zni ('wiederholt Bedingungen aufstellen, Wenn einwenden') gebildet und daraus wieder die abstrakte substantivische Weiterbildung ha-zás há-zás ('[wiederholtes] Aufstellen von Bedingungen mit wenn').

Beinahe ebenso verbreitet ist das substantivierte de ('das Aber/Jedoch'): das grosse Erläuternde Wörterbuch der Ungarischen Sprache (ÉrtSz.) gibt es auch an. Mein frühestes Beispiel dafür ( $a$ ' sok De - De kifogásokkal 'mit den vielen "aber-aber"-Ausreden') stammt aus dem Jahre 1827, das des erwähnten Wörterbuches aus der Mitte des vorigen Jh.s: De . . ach! a de-t miként tudjam . . megmagyarázni ('Aber ... ach! Wie soll ich dieses Aber [= diesen Einwand] erklären'). Man muss jedoch berücksichtigen, dass die ungarische

\footnotetext{
* Vgl. dt. idiomatisch: "Wenn das Wörtchen wenn nicht wär, wär mancher Mann ein Millionär."
} 
Sprachgeschichte - besonders was die selteneren Nuancen der Wortbedeutung bzw. der Wortart betrifft - meines Erachtens noch immer nicht genügend genau bekannt ist. Im Jahre 1972 erschien auch das aus dem denominalen Verbum de-zni ('Einwände machen, protestieren') gebildete nomen actionis De!-zés ('wiederholtes Protestieren') in der Presse. Das einschränkend-adversative hanem ('sondern') ist vorläufig ebenfalls seit 1827 alleinstehend belegt: Annyi Hanemmel állanak elé ('Sie treten / man tritt mit soviel "sondern" hervor'). Dessen völlig selbständiger, substantivischer Gebrauch ist jedoch bei weitem nicht so allgemein, wie es bei de der Fall ist. Statt "Alternative" liest man dagegen nicht selten die schon erwähnte Doppelkonjunktion vagy-vagy in vollkommen abstrakter Funktion. Ein Beispiel aus einem Zeitungsartikel vom Jahre 1963: Valóban Russell vagy-vagyáról van szó ('Es handelt sich in der Tat um Russells Alternative'); und ein zweites aus einer philologischen Zeitschrift vom Jahre 1961: [Némely kérdésben] nem a "vagyvagy", hanem a bizonyos értelmü "is-is" hozza a jó megoldást ('In manchen Fragen] bringt nicht das "'entweder-oder", sondern das in bestimmtem Sinne genommene "sowohl-als auch" die gute Lösung'). In einer wissenschaftsgeschichtlichen Abhandlung von 1960 über die orthodoxe Sprachpflege lesen wir ebenfalls: Az egyes kérdésekhez [e tudósok] . . mindig a vagy-vagy, sohasem a mind-mind elve alapján közelednek ('[Diese Forscher] nähern sich den einzelnen Fragen immer aufgrund des Prinzips von en twe de $r$-oder, nie des von sowohl-als a u ch').

Über die phonetischen bzw. morphophonologischen Folgen der behandelten wortartlichen-funktionalen Verschiebung von Konjunktionen lassen sich ziemlich wenige Feststellungen machen.

Vor allem möchte ich darauf hinweisen: während die meisten ungarischen Bindewörter in ihrer ursprünglichen Anwendung unbetont ausgesprochen werden, erhalten sie dagegen, mehr oder weniger substantivisch gebraucht, gewöhnlich einen klaren Akzent. Dieser ist in den Konjunktionssätzen (-gliedsätzen) auffallend stark: 'Magától jött rá, vagy hallotta valakitöl?"' 'Is-is, hogy a legújabb kiszólást használjam' (' 'Sind Sie von 
selbst darauf gekommen oder haben Sie es von jemandem gehört?" - "Sowohl ...als auch, um die neueste Redensart zu verwenden", '; s. 1969: E. Urbán, A nagy kaland 221). Da trägt also die als Einheit genommene Doppelkonjunktion is-is den Satzakzent, obwohl ihre Bestandteile gewöhnlich unbetont bleiben würden: 'Te is, ö is meg vagytok hiva"' (" 'Sowohl du, als auch er seid eingeladen"'). Im folgenden Beispiel trägt dagegen die Phase mindig csak den Satzakzent, und auf das als Substantiv geltende Bindewort fällt lediglich der weniger starke "Phasenakzent"': még mindig csak az elso" "de"-nél tartott [a felszólaló] ('[Der Redner] war noch immer beim ersten "'aber" '; aus dem Artikel von R. Falus, s. die Nummer vom 25. 10. 1960 der literarischen Wochenzeitung Élet és Irodalom).

Beim Suffigieren der substantivisch verwendeten Konjunktionen ist eine Zwiespältigkeit festzustellen. Bei einem Nomen mit dem Auslautvokal a/e im Nominativ treten bekanntlich im allgemeinen die meisten Suffixe an die Stammvariante mit langem Vokal (álé) im Auslaut: óra ('Stunde; Uhr'), Akk. órá-tleke ('Pflug'), Akk. eké-t. In den letzten hundert Jahren kommt es aber auch in diesem Typ immer wieder vor, dass Zitate, ungewöhnlich gebrauchte Wörter (vorwiegend fremdsprachige Ausdrücke) mit unveränderter Stammform die einschlägigen Suffixe annehmen: az ö tiszteskedö 'aláz'-szolgája!' -ira mindig kurtán . . . köszönt vissza az anyám ('Auf seine beehrenden "'Untertänigster Diener!' dankte meine Mutter stets kurz') - schrieb Margit Kaffka in einem Roman schon 1912. Hogy hol szedte fel szótárába [B.] ezt az "abszolute"-t ('Woher nur dieses "absolute" in seinen Wortschatz [B.s] gelangt war') - möchte Gábor Goda in einem seiner Romane wissen. (Vgl. Magyar Nyelv 56 [1960], 344-56.) Bemerkenswert ist nun, dass nach meinen Angaben z.B. die Formen ha-t (Akk.), ha-k (Plur. Nom.) de-t, de-k die herkömmlichen há-t, $h a ́-k / d e ́-t$, dé-k langsam zurückdrängen. Das lässt darauf schliessen, dass selbst diese beiden - am stärksten substantivisch gebrauchten - Konjunktionen als auffallende Sekundärerscheinungen für die Sprachgemeinschaft gelten.

In der ungarischen Grammatik ist es selbstverständlich, dass die substantivierten Bindewörter nach Bedarf auch als Quali- 
tätsattribute angewendet werden können: das Syntagma vagyvagy megoldás ('eine entweder-oder-Lösung') - kommt bei dem Romancier Ernő Urbán vor; [a megoldás] nem vagy-vagy jellegü ('[die Lösung] hat nicht den Charakter einer Alternative') - schrieb unlängst der Linguist László Antal; az ilyen mégis és mégsem ember ('ein solcher "doch'- und "doch nicht'-Mensch') - ist ein merkwürdiger Ausdruck des bereits verstorbenen Romanciers und Dramatikers László Németh; der ebenfalls schon verschiedene Prosaschriftsteller Béla Illés gebrauchte einmal den Ausdruck egyrészt-másrészt álláspont ('ein einerseits-andererseits [ = allzu grübelnder, unbestimmbarer] Standpunkt'); usw. Aber diese syntaktische Möglichkeit entspricht den nicht nur im Deutschen bekannten losen $\mathrm{Zu}$ sammensetzungen vom Typ Quasi-Theater.

3. Die ungarischen Postpositionen entsprechen als Formwörter bekanntlich den indoeuropäischen Präpositionen. Sie werden viel seltener selbständig und noch weniger rein substantivisch wie die Konjunktionen angewendet. Es ist merkwürdig, dass die aus den lateinischen Präpositionen pro bzw. contra entstandenen, von der jahrhundertelang gebrauchten lateinischen Fachsprache der Jura übermittelten Substantive pró ('das Pro od. Für') und kontra ('das Kontra od. Wider') selbst in der heutigen Gemeinsprache üblich sind, während aus den einschlägigen ungarischen Postpositionen mellett ('neben') und ellen ('gegen') keine ähnlichen Substantive entstanden sind. Das englische Wort topless, das deutsche oben ohne wurde in der ungarischen Presse mit fölül semmi (etwa: 'oben nichts'), nicht aber mit fölül nélkül (wörtlich: 'oben ohne') übersetzt. In der Schriftsprache kommt es allerdings bei den modernen Dichtern hie und da vor, dass eine Postposition als Überschrift von Gedichten, bei Journalisten als Titel von Zeitungsglossen dient. So führt ein Gedicht von Ágnes Nemes Nagy die Überschrift Között ('Zwischen'): im Text kommt dann unter mehreren substantivischen Ein-Wort-Sätzen auch dieses alleinstehende Között vor. Imre Simonyi veröffentlichte 1976 ein Gedicht unter dem Titel Után ('Nach'); Fölött-alatt ('ÜberUnter') und Mellett ('Neben') sind Titel von András Mezei's Gedichten. György Timár gab wiederum seinem Gedicht, das 
den dichterischen Stil von Amy Károlyi parodisiert, 1977 die Überschrift Nélkül: diese Dichterin betont nämlich in ihren Gedichten oft ihr Mangelgefühl, das Fehlen glückverheissender neuer Erlebnisse. - In einem Wochenblatt für Film, Theater und Musik erschien 1977 eine Glosse unter dem Titel Helyett ('Anstatt'): darin werden die Theaterdirektionen getadelt, weil diese bei plötzlichem Programmwechsel "statt" des zuvor angekündigten Stückes ein anderes, einem ganz anderen Geschmack entsprechendes bringen: da sei das Wort helyett ('anstatt') vollkommen fehl am Ort. - Im Gedicht Idöjáték ('Zeitspiel') von Béla Horgas werden die temporalen Postpositionen elött ('vor') und után ('nach') als selbständige Benennungen von Zeitpunkten gebraucht; z.B. az elöt t . . . szabadsága ('die Freiheit des . . . "vor"' '; s. Magyar Nemzet vom 30. 4. 1978).

In Fachsprachen kommt es natürlich auch vor, dass eine Postposition ohne vorangehendes Substantiv gebraucht wird, was jedoch allgemein auf einen noch niedrigeren Grad von Abstraktion hinweist. Ich war vor Jahren Ohrenzeuge, als in der Administration eines wissenschaftlichen Kongresses die Anmeldeformulare daraufhin untersucht wurden, ob sich der Unterzeichnete mit oder ohne Begleitperson anmeldete. Anfangs wurde dabei jeweils der vollständige Ausdruck zitiert: "Kísérö nélkül'" (',Ohne Begleiter"') bzw. "Kísérövel"' (','Mit Begleiter', '); später aber sagte man abkürzend nur die Postposition nélkül bzw. das Komitativsuffix -vel. Den Anwesenden gaben diese formell auffallend unvollständigen Sätze wegen der bekannten Situation bzw. des Kontextes volle Informationen. Lajos Mizser erwähnte in einem Zeitungsartikel (Magyar Nemzet vom 11. 12. 1977), dass im Lebensmittelhandel statt gyulai bzw. csabai módra készitett kolbász ('Wurst nach Gyulaer bzw. Csabaer Art') mit abkürzender Begriffsübertragung nur módra-kolbász (etwa: 'Wurst nach . . .') gesagt wird. Da wurde also aus der unlängst entstandenen Postposition módra das attributivische Vorderglied eines Kompositums. Es soll auch nicht ausser acht bleiben, dass aus Postpositionen, also aus einfachen Formwörtern seit der Sprachneuerung Ableitungen mit vorwiegend denominalen Bildungssuffixen entste- 
hen: alatt-i ('unter etwas befindlich'), fölött-es ('[in einer Hierarchie] höherstehend'), nélkül-özni ('entbehren'), után-ozni ('nachahmen') usw. Aber selbst einschliesslich dieser Entwicklung ist der selbständige bzw. abstrakte Gebrauch der Postpositionen im heutigen Ungarisch ziemlich unbedeutend, sowohl im dichterischen Stil als auch in den Fachsprachen.

4. Die einschlägige Umwandlung der $\mathrm{H}$ il f $\mathrm{s}$ v e $\mathrm{r}$ b e $\mathrm{n}$ bietet uns wieder etliche anders geartete Schlüsse. Im Perfekt des Konditional-Optativs wird z.B. das Hauptverb im Perfekt des Indikativs personalsuffigiert, während sich diesen Formen das unflektierte Hilfsverb volna (eigtl. 3. Sg. Präs. des Kond. vom Existenzverbum van) zugesellt. Dieses Hilfswort kommt dann im Alltagsungarisch und in der Prosaliteratur nicht selten selbständig vor: als Ausdruck der abstrakten Modus- (und Tempus)bedeutung, also der Irrealität, des Zweifels, der Unwiderrufbarkeit. Im folgenden Beispiel dient es zum Ausdruck der Empörung über den unbegründeten Zweifel: "Mikor történt volna ez?" - "Volna? Ötvenhatban" (",Wann wäre das geschehen?" - "Wäre?! Im Jahre 1956" '; aus einem Roman von Ernő Urbán). Emil Kolozsvári Grandpierre schrieb 1978 in einem Essay: Az önismeret forrása mindig az összehasonlítás, mint ahogy a színészi [játék jellemző szava] . . a mintha, s a történetíróké . . a voln a. Ha ugyanis nem képzeljük el, hogy adott helyzetben a történeti személy, azonkivül, amit rosszul csinált, mi mást csinálhatott voln a - nem minösíthetjük elhibázottnak ... politikáját ('Die Quelle der Selbsterkenntnis ist immer der Vergleich, wie [das charakteristische Wort für das Spiel] der Schauspieler... das als ob, und das der Geschichtsschreiber das hät te/wäre ist. Wenn man sich nämlich nicht vorstellt, was die historische Person in der gegebenen Situation ausser dem, was sie schlecht gemacht hat, anders hät te tun können - kann ihre Politik nicht als verfehlt hingestellt werden'). Und Miklós Jovanovics beendete seine Filmkritik 1973 in einem Tageblatt wie folgt: Éppen ezért gondoljuk [a jubileumi Jókai-filmre vonatkozólag], hogy a költségvetésbe belefért volna a teljesebb Jókai. [Új bekezdés:] Volna. ('Eben deswegen glauben wir [in bezug auf den Jubiläumsfilm über Jókai], dass im Etat auch ein vollständigerer 
Jókai Raum gefunden hätte. [Neuer Absatz:] Hätte'.) In diesem letzten Fall drückt das als Abschluss selbständig wiederholte Hilfswort volna klar aus, dass die Möglichkeit endgültig verpasst wurde. - Es ist aber in allen drei Beispielen festzustellen, dass man die flektierte Form, den Indikativ Perfekt des Hauptverbs mehr oder weniger aus dem Kontext auch dazuverstehen kann; am wenigsten im zweiten Beispielsatz, wo volna als abstraktes Nomen - ein Korrelatum des ebenfalls abstrakt und substantivisch gebrauchten Bindewortes mintha - schon weit früher genannt wird als die vollständige "zusammengesetzte" Verbform történt volna. - Die gänzliche Abstraktion bzw. Substantivierung dieses Hilfsverbs wird wahrscheinlich dadurch gehemmt, dass dieselbe Form volna gleichzeitig zum Präsens des Konditionals vom Verbum van 'ist' gehört. Sprichwortartige Sätze wie $H a$ az a volna nem volna, minden jobb volna ('Wenn dieses "volna" [= wäre/hätte] nicht wäre, wäre alles besser') können sich sowohl auf das Hilfswort des Perfekts als auch auf den Konditional Präsens von van beziehen.

Das flektierte Hilfszeitwort fog des Futurs steht - wie bekannt - neben dem Infinitiv des Hauptverbs: irni fogok ('[ich] werden schreiben'). Da diese Einheit selbst bis heute etwas vom ursprünglichen Rang eines Objektsyntagmas beibehalten hat, kann man eine vollkommene Substantivierung des Hilfsverbs noch weniger erwarten als im vorigen Fall von volna des Konditional Perf. Ich will also auf dessen genauere Untersuchung hier gar nicht eingehen. Als Zitat kann aber selbstverständlich auch dieses Hilfsverb - substantivisch wiederholt in den Satz eingefügt werden. Im folgenden Beispiel von Iván Boldizsár geschieht das nicht einmal, um es als den Träger der Futurbedeutung, sondern lediglich um den Träger des Personalsuffixes der 1. Pers. Sg. bzw. Pl. zu erläutern: gondokról és akadályokról fogunk beszélni [az értekezleten]. - Ez a fogunk itt nem afféle felséges többes szám, hanem valóban sok embert jelent, és a maga módján modern felséget, a népek küldötteit, az Unesco 121 tagállamának képviselöit ('Wir werden von Sorgen und Hindernissen [auf diesem Kongress] reden. Dieses "[wir] werden" ist hier kein sog. Majestätsplural, 
sondern es bedeutet in der Tat viele Menschen und auf eine andere Art eine moderne Majestät: die Delegierten der Völker, die Vertreter der 121 Mitgliedstaaten der UNESCO'; s. 1975: A szárnyas ló 221). Der Hinweis auf den Unterschied zwischen der 1. Person Sg. fogok ('[ich] werde') bzw. des Plurals fogunk ('[wir] werden') wäre mit dem Benennen des blossen Personalsuffixes -ok bzw. -unk für den Leser wahrscheinlich nicht deutlich genug; die Wiederholung des unflektierten Teils des Futurs (beszélni) ist jedoch bereits überflüssig, vollkommen irrelevant.

5. Nunc venio ad fortissimum! Die Verselbständigung der Suffixe ist vor allem bei den produktiven A bleitungs suffixe n leicht zu verstehen: diese sind sowohl ihrer Form als auch ihrem - der Stammbedeutung addierten - Bedeutungsimpuls nach meistens leicht zu unterscheiden. Wenn nun der für die ungarische Sprache so kennzeichnende Reichtum an Wortbildungselementen in den Schulen genügend behandelt - das heisst hier: bewusst gemacht - wird, so ist der Weg für unseren sprachpsychologischen Vorgang schon offen. Auf die vollständige Angabe der einzelnen Ableitungssuffixe in der Sprachwissenschaft will ich hier natürlich nicht eingehen; auch soll nur eben erwähnt werden, dass selbst die Sprachgeschichte ein-zwei vereinzelte Fälle für diese Abstraktion registriert hat. So entstand z.B. zur Zeit der Sprachneuerung aus der alten Ableitung szélhüdés das "einfache" Substantiv hüdés hüdés ('Schlaganfall'); unsere Generation kennt auch das Substantiv izmus ('eine [vorwiegend avantgardistische künstlerische] Richtung') aus dem Suffix der aus dem Lateinischen entlehnten Fachwörter Impressionismus, Expressionismus, Kubismus usw.

Die Hauptquelle des bewussten Gebrauchs dieser Abstraktion ist meinen schriftlichen Daten nach die Roman- und Novellenliteratur sowie die Dichtkunst der letzten Jahrzehnte. Am bekanntesten ist vielleicht das Beispiel des Karitivsuffixes -t(a)lan/-t(e)len, -atlan/-etlen ('etwas entbehrend, -los'). Die Hauptvariante -talan/-telen ist meines Wissens zuerst 1939 als selbständiges Attribut angewendet worden: Talantelen bácsit hét év óta ismerem ('Onkel "Ohne" kenne ich seit sieben 
Jahren'). Béla Zolnai zitierte diesen Satz sogleich nach seinem Erscheinen in einer Zeitungsnovelle mit der Bemerkung des Autors: 'Mint a-talan, vagy a-telen, ami megfoszt, de amellett maga se vitte annyira, hogy szó lett volna a maga lábán ('Wie das -talan oder -telen, die jemandem etwas entziehen, es selbst aber dabei nicht soweit gebracht haben, als Wort auf eigenen Füssen zu stehen'; s. neu herausgegeben in Béla Zolnai, Nyelv és stílus 212). Der Schriftsteller war also völlig überzeugt, dass sein als Adjektiv gebrauchtes Talantelen noch kein selbständiges Wort sei. Heutzutage wird das kaum betont. Amy Károlyi gab 1972 ihrem poetischen Sammelband (und darin dem dadurch hervorgehobenen Gedicht) den Titel -talan-telen ('-los/ohne [etwas]'). Im Band Fosztóképzökkel ('Mit karitiven Ableitungssuffixen') beginnt Péter Fábri das entsprechende Gedicht mit den Worten: Minden olyan | t a la n és te le $n \mid$ talán nem is reménytelen (etwa: 'Nicht jedes "ohne" und "bloss" ist vielleicht so hoffnungslos'; vgl. Zsolt Köháti, Magyar Nyelvőr 97 [1973], 182-8 und J. Tompa, Anyanyelvi olvasókönyv 274). György Timár wendet in seiner bereits erwähnten Stilparodie auf Amy Károlyi auch andere Wortspiele mit den substantivierten Karitivsuffixen -talan/-telen bzw. -tlan/-tlen an: diese lassen sich aber nicht auf die entsprechende Weise ins Deutsche übertragen. - Im gesprochenen Fachjargon der Ärzte wird nach János Ladó's Behauptung statt keresőképtelen ('erwerbsunfähig') lediglich das verselbständigte telen gebraucht (s. in L. Grétsy red., Mai magyar nyelvünk 13). Die Anwesenden verstehen den relativen Wortstamm keresökép- ebenso von selbst wie in meinem oben erwähnten Beispiel der Postposition nélkül ('ohne') das Substantiv kisérö ('Begleiter') aus dem Kontext hinzuverstanden wurde. Diese Fälle sind zwar auch aufschlussreich, zeugen aber noch nicht für einen höheren Grad der Abstraktion.

Der Held einer Novelle von György Moldova egy nö régi megjegyzését hallotta [álmában]: 'Te mindig eskedsz: eredetieskedsz, érdekeskedsz" ('hörte [in seinem Traum] die lange zurückliegende Bemerkung einer Frau: "Du -eskedsz [etwa: -erlst/-ierst] immer: willst dich originell, interessant aufspielen"'). Dieser Staz wird einer Frau von heute in den Mund 
gelegt, er kann also als Beweis dafür dienen, dass solche Abstraktionen hie und da auch in der gemütlichen Konversation von Intellektuellen vorkommen. Der frequentative Suffixblock -skodik/-skedik/-sködik kann nämlich auch mit einem Bindebzw. Vorvokal gekoppelt werden; die so entstandene Formvariante -esked- erhielt dann in unserem Fall das subjektive Personalsuffix der 2. Person Sg. $-s z$. - Bemerkenswert ist noch, dass die selbständig gewordene (zusammengefügte) Endung -eskedsz die Bedeutungsimpulse der enthaltenen Suffixe zwar abstrakt ausdrückt, jedoch mit voller Beibehaltung der wortartlichen Teilbedeutung des fehlenden Grundverbs: sie wird als Prädikatsverbum gebraucht. Ambrus Bor schreibt 1975 in einem Essay, dass die Lokalpatrioten befürchten, ihre Provinzfärbung zu verlieren, z.B. das hajdúsági kolorit ('Kolorit des Komitates Hajdú-Bihar') oder alföldiség ('das Charakteristische der Tiefebene von Ungarn'). Er selbst behauptet gegen diese Menschen: Ság és ség: provinciális romantika ('Ság und ség [etwa: -heit/-tum], das ist Provinzromantik'). Hier spürt man wieder mehr die Verbundenheit der selbständig gebrauchten abstrakten Substantivbildungssuffixe mit den vorher genannten vollständigen Beispielwörtern. László Hárs empört sich in seiner Replik über das auf ihn bezogene deverbale Frequentativsuffix -gat/-get [etwa: '-ernt/-iert'] seines Gegners: ő tehát nem gat ('sein Gegner tut also nicht "'-ieren" '); "aki gat" ['wer "-ieren" tut'], das ist allein er, L. Hárs: én csak úgy gatok és getek, bele a vakvilágba (etwa: 'ich pflege nur so zu "-ieren", ins Blaue hinein'). Hier blieb das Frequentativsuffix ohne seine Grundwörter, ist also noch abstrakter als es das -eskedsz vorher war; es wird ebenfalls als selbständiges Verbum konjugiert. - Und zuletzt ein Beispiel ganz anderer Art: nun vertritt nämlich die Abstraktion des Suffixblockes das pathologische Symptom eines manifesten Geisteskranken; die psycholinguistische Basis ist jedoch bis zu einer gewissen Grenze dieselbe, die wir in den obigen Sätzen gesehen haben. Der Nervenarzt István Benedek schreibt über einen Patienten in der arbeitstherapeutischen Heilanstalt, einen Schlosser. Der möchte sich noch immer aus der Gewalt derer befreien, die alles von anderen verrichten lassen, "a ta tók és te tỏk rabságából" 
('aus der Gefangenschaft der "'Lassenden"'), "akik átkos sugaraikkal fogságban tartat-tat-tat-tatják' ('die mit ihren verdammten Strahlen ihn gefangen halten "lass-lass-lass-lassen" '). Er weiss zwar, "hogy nem ön a hibás ebben, hanem a "tatók" és 'tetök", akik sugaraztat-tat-tatják az embert ('dass nicht Sie [= der Arzt] daran schuld sind, sondern die "Lassenden", die einen bestrahlen "lass-lass-lassen"' '). Im Ungarischen wird nämlich das Faktitivum durch die Ableitungssilbe -at/-et bzw. -tat/-tet aus dem Grundverb gebildet; tatóltetö ist ein imperfektes Partizip, aus den markantesten Varianten dieses Suffixes gebildet; tatók/tetök wiederum der Plural dieses hauptwörtlich gebrauchten fiktiven Partizips.

6. Zuletzt kommen die selbständig gewordenen, mehr oder weniger substantivierten Flexions suffixe zur genauen Untersuchung, die mich eigentlich am meisten interessierten.

a) Als Einleitung zu den nominalen Suffixen muss ich den Leser aufs neue daran erinnern, dass die Situation es innerhalb eines kleineren Kreises möglich macht, das drittevierte Mal statt kísérövel ('mit [einem] Begleiter') einfach -vel zu sagen, ohne die Klarheit, Eindeutigkeit der Kommunikation zu gefährden. Aus der immer grösseren Gemeinschaft der einzelnen Fachsprachen für Industrienormen, Spedition, Wirtschaft kam auch das "Wort" tól-ig in allgemeineren Gebrauch. Die Suffixe -tól/-töl ('von/seit') und -ig ('bis') standen nämlich in den sogenannten doppelten Adverbialien (auf die Frage woher-wohin, seit wann-bis wann usw.) miteinander in enger Korrelation: so ist es kein Wunder, dass am Ende aus diesen unselbständigen Wortelementen eine ziemlich feste, lexikalisierte Zusammensetzung entstanden ist. In einem halbamtlichen Handbuch der gültigen Rechtschreibung findet man: tól-ig norma (etwa: 'die von-bis-Norm'), tól-ig-os bérrendszer ('Lohnsystem mit von-bis-Grenzen'); in den Zeitungen auch mit anderer Orthographie: a "'-tól . . -ig"' határok bövitésével [fokozni lehetne az ösztöndíjakat] (' Durch eine Erweiterung der von-bis-Grenzen [könnten die Stipendien erhöht werden]'); $A z$ alkalmasság -tól-ig határa ('Die von-bis-Grenze der Tauglichkeit': Überschrift eines Artikels); usw. - Warum sich die velare Variante -tól in dieser Verbindung festigte, wo doch die 
entsprechenden personalsuffigierten Formen tölem ('von mir'), töled ('von dir'), töle ('von ihm/ihr') usw. eher die palatale Variante empfohlen hätten, ist schwer zu sagen. Meiner Ansicht nach konnte der in der Spedition seit langem alltägliche Ausdruck háztól házig ('von Haus zu Haus') als Ausgangspunkt dienen.

Als György Somlyó die von ihm ausgewählten und übersetzten Gedichte von Eugène Guillevic 1973 in einem Band erscheinen liess, gab er dem Buch sowie einem darin übermittelten Zyklus den Titel $V A L$ [darunter:] $V E L$ bzw. $V A L-V E L$ ('mit', aber im allgemeinen als Suffix gebraucht). Er entspricht dort den französischen Überschriften Avec, also einer verselbständigten Präposition, die im grossen und ganzen dieselbe syntaktische und semantische Funktion erfüllt wie das ungarische Kasussuffix -vall-vel. Das Beispiel beweist gleichzeitig, dass begabte Übersetzer dichterischer Werke manchmal durch die Inspiration eines fremdsprachigen Ausdruckes eine grammatische Form bilden können, die in ihrer Muttersprache viel neuartiger ist als das fremde Muster in der Quellensprache. Der selbständige, quasi-substantivische Gebrauch der französischen Präposition avec ist in der französischen dichterischen Sprache viel weniger überraschend als bei uns der des -vall-vel: unter anderem weil avec rein phonetisch genommen ein richtiges Wort ("freies Morphem") ist, während -vall-vel bisher ausserhalb der Fachsprache der Grammatik - nur als Suffix ("gebundenes Morphem") gebraucht wurde. - Die Anmerkungen des genannten ungarischen Bandes interpretieren den überraschenden Titel nicht; man kann nur ahnen, dass dieser als Symbol auf die Wechselbeziehungen zwischen den Dingen der Umgebung und dem Bewusstsein des Dichters anspielt. Dezső Tandori gebraucht in seinem - an allerkühnsten Sprachmitteln reichen - grossen Poem aus dem Jahre 1977 denselben neu geschaffenen Ausdruck: és alatta apró betükkel | még, hogy antarktiszi program, amely kezdödött |-val, -vel (etwa: 'und darunter noch mit kleinen Buchstaben, dass das Antarktis-Programm, das mit [+ $\emptyset$ ] begann'). Und in diesem Werk findet man auch das plurale Possessivsuffix der 3. Person Sg. ebenso ohne ein vorangehendes Stamm-Substantiv: így folytatódik a szöveg: 
. . jai (emlékezzünk: céljai!) ('der Text wird fortgesetzt: seine ... (erinnern wir uns: seine Ziele!)'). Da wird also dem lückenhaften Wortteil . . . jai in Klammern das schon erwähnte vollständige flektierte Substantiv zugefügt. Ich brauche nicht zu betonen, dass dieses "Suffixwort" . . . jai nur als eine extreme Einmalbildung betrachtet werden darf; neben den übrigen ähnlichen Neuerungen der dichterischen Sprache deutet jedoch auch dieses auf das merkwürdige Phänomen der heutigen Literatursprache.

In der Alltagsrede - vorwiegend unter der Jugend - und in der Presse ist das einzig vollwertige Nominalpräfix des Ungarischen, das leg- (etwa: 'am meisten') des Superlativs ziemlich allgemein als selbständiges Lexem verbreitet. Seine Bedeutung ist vor allem adjektivisch: '(in gutem Sinne) erster, grösster, bester', jedoch wird öfters auch die Bedeutung des möglicherweise darauffolgenden - nicht ausgesprochenen Beiwortes hinzuverstanden. Deshalb setzt man manchmal drei Punkte danach: Leg . . . ist z.B. der Titel einer Glosse aus dem Jahre 1963, die eine Zeitungsnachricht bezweifelt, wonach die France das grösste Passagierschiff der Welt sei. Melyik autó a leg . . .? (etwa: 'Welche Automarke ist die . . . ste?') - lautet die Überschrift eines Artikels aus dem Jahre 1964. Auch können Anführungszeichen die Aufmerksamkeit auf den seltsamen Gebrauch des Präfixes lenken: a sok "leg" között az is ott van, hogy "legtökéletesebb' ('unter den vielen Superlativen ist auch das [zu finden], dass [es das] "vollkommenste" [ist]') lasen wir 1962 in der Presse. 1957 auch: a 'leg'-eket elhagyhatjuk ('die Superlative kann man weglassen'); 1975 ebenfalls: [S. L.] "leg"'-gel jellemzett tíz világhírü férfisztárt ('[L. S.] kennzeichnete zehn weltberühmte männliche Stars mit Superlativen'); und neuestens wieder: A "'legek" éve ('Das Jahr der Superlative/Bestleistungen'; als Titel, s. Magyar Nemzet vom 7. 2. 1978). Es wird auch mit anderer Setzart beim Druck unterschieden: hogy a világ leg jeit összegyüjtse ('um die [Hervorragend]sten der Welt zu sammeln'; aus d.J. 1975). Es kommt aber auch ohne jeden Unterschied in der Schrift vor, z.B. in der letzten Quelle weiter: hogy a legek legszebbjeit ne mazsolázzam ki ('damit ich nicht die schönsten der Superlative 
[als Rosinen] herauspicke'). Charakteristisch ist auch, dass der letztgenannte Text (von Tamás Ungvári) die Exzessivform des Präfixes als Titel führt: Legesleg ('Am aller . . . sten'); und dass in einem aus dem Englischen (von Mária Déva) übersetzten Roman die Weitersteigerung von leg vorkommt: $a \ldots$ leglegebb fickóhoz (etwa: 'zum aller-aller[er]sten Kerl'). Diese gesteigerten Formen lassen darauf schliessen, dass leg seine superlativische Färbung bereits einzubüssen beginnt, so dass diese auf irgend eine andere Weise verstärkt, weitergesteigert werden muss. (Auf die abstrakte Substantivierung des leg- habe ich kurz schon 1961 in der "Akademischen Grammatik" MMNyR. 1, 162 hingewiesen. Historisch genommen hat sich dieses Präfix aus einem adverbialen Vorderglied von Komposita entwickelt: in diesem Sinne ist also seine Verselbständigung auch mit der Abstraktion der ersten Glieder von zusammengesetzten Wörtern verwandt. S. a.a.o. 1, 463.)

b) Die Lexikalisierung der Konjugations $\mathrm{k}$ ffixe ist im allgemeinen noch seltener, besonders wenn man von den ephemeren Parole-Erscheinungen absieht. Doch betrachten wir zunächst einen solchen Fall! 1953 hörte ich, wie ein Mann in einer intimen Gesellschaft zufrieden feststellte: "No, ezt gyorsan megcsináltuk!' (' "Na, das haben wir schnell gemacht!','), worauf sein Gesprächspartner das Personalsuffix des Prädikatsverbum nüchtern verbesserte: 'Tuk?! Tam! Hisz én csináltam meg, te csak nézted!' (etwa: ' 'Haben?! Habe! Das hab' doch ich gemacht, du hast nur zugeschaut!' ') Bemerkenswert ist, dass wir Anwesenden den Sinn dieser beiden kleinen emphatischen Wortsätze - aus je einem Suffixblock - in Kenntnis des Kontextes bzw. der Situation voll verstanden haben. Auch das war für uns selbstverständlich, dass sich zwar die Berichtigung nur auf die objektiven Personalsuffixe -am bzw. $-u k$ bezog, diese Reaktion aber immer mit dem Suffix des Perfekts - $t$ beginnen musste: so hatte die Kommunikation allerdings ein wenig Redundanz, doch sie schaltete gleich die Möglichkeit des Missverstehens aus. Die Wiederholung des Verbalstammes megcsinál- ('mach-') schien dagegen ganz und gar überflüssig. (Vergleiche dies mit einem Beispiel in Punkt 4., wo die Interpretation der subjektiven Personalsuffixe -unk bzw. 
-ok auch die Wiederholung des ganzen Hilfswortes fogok und fogunk benötigte, während das Nennen des infinitivischen Teiles der vollständigen Futurformen überflüssig war.)

Gehen wir nun auf eine andere Entwicklung über, die ihren Ursprung in der Sprachwissenschaft hatte, die aber heutzutage auch im Gebrauch der Ungarischlehrer, der Redakteure und vieler anderer Intellektuellen gang und gäbe ist. Dazu muss man wissen, dass die objektiven Verbformen in der Hochsprache bei bestimmten Stämmen auf $t$ im Präsens des Indikativs, in der 1 . Person Plural statt auf $-j u k /-j u ̈ k$ im Volksmund auf $-s u k /$-sük enden. Um das Jahr 1950, wo sich diese Formen sogar in der Gemeinsprache zu verbreiten drohten, nannte die Sprachpflege diesen Gebrauch - mit einem gewissen Hohn - suksük-Sprache. Dieser Ausdruck verbreitete sich im genannten Bereich ziemlich stark, obwohl das Phänomen selbst heute gar nicht mehr so verbreitet ist. So ist z.B. bei dem Linguisten Miklós Kovalovszky suksük-nyelv ('Sprache mit -suk/-sük') zu lesen (s. 1969: Deme-Köves red., Magyar nyelvhelyesség. 4. Ausgabe, 193). Ein Beispiel für den substantivischen Gebrauch der Endungen: [A képzetlen tanár] Mondataiból $a s u k-s \ddot{u}$ $k \ddot{o} k$ oly otthonosan röpködtek ('Aus den Sätzen [des ungebildeten Lehrers] flogen die suk-sük's so heimisch umher'; s. das literarische Wochenblatt Élet és Irodalom vom 10. 12. 1977). Das aus diesem "Suffixwort" abgeleitete Verbum suk-sük-özni ('mit -suk/-sük sprechen') sowie das daraus weitergebildete suk-sük-özés ('das Sprechen mit -suk/-sük') sind ebenso bekannt.

In der Lyrik erscheinen solche verselbständigten Verbalsuffixe nur ganz selten. $\mathrm{Zu}$ nennen ist hier allerdings das Gedicht von István Pákolitz mit dem Titel Nanenáné (etwa: 'Würd-'). Das Wort entstand aus den vier Hauptvarianten des Modalsuffixes für den Konditional-Optativ -na/-ne, -nál-né der Schulgrammatiken. Der Autor wollte damit auf seine Sehnsucht hinweisen. Die ersten vier Zeilen enthalten dann vier Wunschsätze mit den verbalen Prädikaten fogdosna, görgetne, megcukrozná, odaítélné ('er/sie möge/würde ergreifen, wälzen, [es] zuckern, bescheiden'); die letzten vier Verse bestehen lediglich aus den angewendeten Suffixvarianten, als Ausdruck der alles überwältigenden Sehnsucht: $N a .|N e| N a. ́ . \mid N e ́$. 
Das Verbalpräfix fungiert im Ungarischen - wie auch in anderen Sprachen - zum Teil als Bildner perfektiver, momentaner, kursiv-durativer usw. Verben, zum Teil aber als adverbiales Vorderglied von Komposita: vgl. einerseits mond ('er/sie sagt') aber megmond ('. . . sagt aus'); andererseits megy ('. . . geht'), aber felmegy ('. . . geht hinauf'). Die beiden Funktionen sind miteinander zumeist eng verschmolzen, so dass ich die Abstraktion der Präfixe, welche nur Ableitungen zustandebringen, kaum von denen, die eine adverbiale - also syntaktische - Relation ausdrücken, unterscheiden möchte. Die formelle Verselbständigung der Präfixe kann wiederum nicht mit der der vorhergehenden Formantien verglichen werden, da sie ohnehin trennbar sind. Es ist allerdings interessant, dass man auf eine Entscheidungsfrage die bejahende Antwort geben kann, indem man das blosse Präfix des Prädikatsverbs vom Fragesatz - mit entsprechender Satzmelodie - wiederholt: "Megnézted?"' ("'Hast du es [dir] angeschaut?"') "Meg" (' 'Ja" '). - Ein einziges dichterisches Beispiel möchte ich jedoch anführen, wo das nicht adverbialartige, also in der Rolle eines reinen Bildungssuffixes auftretende Präfix meg (etwa: 'ver-/er-') substantivisch das ganz abstrakte Bedeutungsteilchen des Gelingens/der Perfektion vertritt: most már nem megélni akarok: | a "meg' az megvan; most már csak élni. Ami persze, I meg nélkül nem megy (etwa: 'jetzt möchte ich mein Leben nicht mehr erhalten: das "er-" ist gesichert; nunmehr bloss halten/leben. Was natürlich ohne das "'er-" nicht gelingt').

Ausnahmsweise abstrahiert man leider in der Literatur auch solche Verbalsuffixe, die es in der angegebenen Form überhaupt nicht gibt: da verführt also eine falsche Analogie den in der Grammatik unsicheren Autor. Dann hat man den Eindruck, dass die Verselbständigung bzw. Abstraktion von Suffixen manchmal lediglich von einer äusserlichen internationalen stilistisch-literarischen Mode unserer Jahre gefördert wird.

7. Im ganzen scheint mir diese Entwicklung doch zu bezeugen, dass man selbst heute neue Quellen zur Erneuerung und Ergänzung des Wortschatzes in der innersten Struktur der Sprache sucht bzw. findet. Die Vorgänge der verschiedenen Arten dieser zeitbedingten Abstraktionen finden ihren Ausgangspunkt bald in der linguistischen Fachliteratur, bald in der 
Alltagssprache, bald in den Fachsprachen, bald in der gequälten Seele eines Nervenkranken. Die Presse bedient sich besonders gern der neuesten Errungenschaften der Zeitgenossen; die Dichter finden in ihnen auch oft die Mittel zur kunstvollen Offenbarung ihres Selbst. Die Produkte sind einmal vergängliche Parole-Erscheinungen, ein anderes Mal bleibende Gemeingüter einer sozialen Schicht oder selbst der grösseren Sprachgemeinschaft; sie können todernst, aber auch gekünstelt, beinahe komisch wirken. Was den dichterischen Stil unserer Tage betrifft, wiederhole ich nur einen Satz deutsch aus der Kritik Jenő Alföldys über die Werke von Dezső Tandori: ' Was die Dichter früher nur als Mörtel angewendet und lediglich äusserst sparsam benutzt hatten, das wurde jetzt zur Mauer des Gedichtes, zu Beton oder eher zu leichtem, aber festem Schaum." Der Dichter István Bella sagte 1977 in seinem Buch Igék és igák ('Verben und Joche') unter anderem: A szótövek, félmondatok |ideje jö ('Es kommt das Zeitalter der Wortstämme, der halben Sätze'). Und es gibt zahlreiche weitere Äusserungen über die Zerstückelung der herkömmlichen Ausdrucksformen in der modernen Dichtung. Vgl. I. Szathmári, in Rácz-Szathmári red., Tanulmányok a mai magyar nyelv mondattana köréböl (S. 189-203) und J. Tompa, Anyanyelvi olvasókönyv (S. 270-8).

J. TOMPA 